\title{
Ceramic waste glass fiber-reinforced plastic-containing filtering materials for turbid water treatment
}

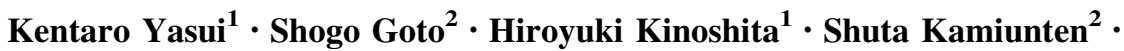 \\ Toshifumi Yuji $^{3} \cdot$ Yoshimi Okamura $^{3} \cdot$ Narong Mungkung $^{4} \cdot$ Mitsuhiro Sezaki $^{1}$
}

Received: 6 March 2016/Accepted: 23 July 2016/Published online: 4 August 2016

(c) The Author(s) 2016. This article is published with open access at Springerlink.com

\begin{abstract}
To utilize waste glass fiber-reinforced plastic (GFRP) and to reduce environmental pollution in rivers and lakes, we developed a filtering material that can clean contaminated water. The high strength and porous nature of glass fiber-reinforced ceramic made by mixing clay and crushed waste GFRP before firing was exploited to do so. Various specimens with different pore size distributions were made by changing the mixing ratio of clay and crushed GFRP, the GFRP particle size, and the mixture firing temperature. Bending strength and permeability tests indicated that several types of ceramics with good permeabilities and adequate bending strengths could be produced, which enables their use as filtration materials for turbid water. Filtration tests on simulated turbid water clarified the relationship between the pore size distribution and the filtering ability of the ceramic for turbid water. Filtration tests on river water verified their practical suitability as ceramic filtration materials. It is proposed that ceramics made from clay and GFRP could be used as filtering materials for turbid water.
\end{abstract}

Hiroyuki Kinoshita

t0d165u@cc.miyazaki-u.ac.jp

1 Department of Engineering, University of Miyazaki, 1-1 Gakuen-Kibanadai-Nishi, Miyazaki 889-2192, Japan

2 Graduate School of Engineering, University of Miyazaki, 1-1 Gakuen-Kibanadai-Nishi, Miyazaki 889-2192, Japan

3 Department of Education and Culture, University of Miyazaki, 1-1 Gakuen-Kibanadai-Nishi, Miyazaki 889-2192, Japan

4 Department of Electrical Technology Education, King Mongkut's University of Technology Thonburi, Bangkok 10140, Thailand
Keywords Waste glass fiber-reinforced plastic . Recycling · Permeability · Filtration · Turbid water

\section{Introduction}

Glass fiber-reinforced plastic (GFRP) is plastic to which glass fiber has been added as a reinforcement material to improve its specific stiffness, strength and incombustibility. GFRP has been used in various products such as automobile parts and small vehicles. However, most waste GFRP is buried underground like other industrial waste. Fine glass fiber dust and leachates from this process may cause serious health and environmental damage, and landfill sites may also become unavailable in the future because of space constraints (The Ministry of the Environment Government of Japan 2015). Therefore, the development of an effective technique for the disposal of waste GFRP without polluting the environment is strongly desired.

There are three categories, mechanical, thermal, and chemical recycling, as technologies to recycle waste plastics (Nagaoka 2008; Yang et al. 2012). These recycling technologies are selectively used depending on the type of waste plastics such as thermoplastic and thermoset plastic.

For mechanical recycling, it is difficult to reproduce new products by reforming the waste GFRP because the products possess a high hardness, even if the matrix of the waste GFRP was thermoplastic. Thermal recycling mainly aims to recover energy utilizing combustion gas generated by burning plastic and additionally aims to recover residual glass fiber. Although the thermal recycling technology can be applied to waste GFRP containing high glass fiber, the amount of energy recovery is smaller than that of waste plastic without glass fiber. Chemical recycling is a process that recovers glass fiber as well as resin by chemically 
dissolving waste plastic or separating glass fiber from plastic. Chemical recycling technology has often been applied regarding waste thermoset plastics to which mechanical recycling technology cannot be applied. The process for the chemical recycling treatment depends on the inherent property of waste plastic.

Total amount of waste plastic in Japan, 2011, was about 9500 kiloton. Twenty-three percent of the total waste plastics have been recycled using mechanical recycling technologies, $53 \%$ of those have been recycled using thermal recycling technologies, and $4 \%$ of those have been recycled using chemical recycling technologies (Plastic Waste Management Institute of Japan 2013, 2015). Chemical recycling has not been conducted much in Japan. It is thought that the chemical recycling treatment lacks versatility and needs a high cost. As stated above, the existing recycling technologies are not enough to recycle waste GFRP containing high glass fiber.

To recycle waste GFRP, we have proposed a process that produces porous glass fiber-reinforced ceramics by mixing clay and crushed waste GFRP before the mixture is fired (Kinoshita et al. 2010, 2011, 2013). This process is not selective toward the type of GFRP and it can also minimize fine glass fiber dust generation by sintering clay and glass fiber, or sintering between glass fibers.

New product materials that are developed from waste are often more expensive than those made from virgin raw materials because they require waste collection, incur volume reduction costs, and yield a lower-quality product. Therefore, a low manufacturing cost and a clear advantage for using the raw material waste are critical (Materials science society of Japan 1999).

Recently, environmental pollution of rivers and lakes by wastewater from households and industrial effluent has become an important problem (The Ministry of the Environment Government of Japan 2013, 2015). Particularly, the deterioration of water quality of lakes such as Biwako and Kasumigaura in Japan has become an urgent issue because the lakes are valuable water resources to people of large cities.

Therefore, we have focused on the water pollution issue. Waste GFRP enables the production of clay-based ceramic with a high porosity and large pore size because the ceramic structure is reinforced with glass fiber. We have aimed to develop filtering materials for improving or preventing water quality deterioration of rivers and lakes by exploiting the properties of porous ceramics made from GFRP and clay. As the first step to the goal, we have attempted to develop a filtering material that can reduce water contamination.

Various specimens with different pore size distributions were made by changing the mixing ratio of clay and crushed GFRP, the GFRP particle size, and the firing temperature. Measurements of porosity, permeability, and bending strength were taken on the resultant samples. The relationships between porosity or pore size distribution and ceramic permeability were examined.

Next, filtration tests on simulated turbid water that contains kaolin or silica powder of different particle sizes were carried out. The relationship between pore size distribution and ceramic filtering ability on turbid water was examined.

\section{Experiments}

\section{Manufacture of ceramics using waste GFRP}

\section{Raw materials}

Figure 1 shows the raw materials used to produce the specimens. Figure 1a shows a clay that is produced in Miyazaki, Japan, for use in brick or tile manufacture. The major mineral of the clay is chlorite. Polyamide plastic pellets that contain $40 \%$ glass fiber were used as waste GFRP. GFRP pellets were used as raw materials to produce specimens after they had been crushed using a rotary mill and had been sifted using a $0.5 \mathrm{~mm}$ or $\sim 0.5-1.0 \mathrm{~mm}$ mesh screen. Figure 1b, c shows two kinds of GFRP powders. Figure 1d shows fine glass fiber of a particle size of approximately $10 \mu \mathrm{m}$ or less that was present in the GFRP.

Table 1 shows the chemical compositions of the inorganic substances in the clay and GFRP after firing. The glass fiber in the GFRP contains $\mathrm{SiO}_{2}, \mathrm{CaO}$, and $\mathrm{Al}_{2} \mathrm{O}_{3}$ as its main components, whereas the clay contains $\mathrm{SiO}_{2}$ and $\mathrm{Al}_{2} \mathrm{O}_{3}$ as its main components. The $\mathrm{CaO}$ component ratio of the glass fiber is larger than that of the clay.

\section{Ceramic production}

Table 2 shows the types of specimens and different manufacturing conditions. We made various disk-shaped specimens of $\sim 44 \mathrm{~mm}$ diameter and $10 \mathrm{~mm}$ thickness as follows:

1. Clay and GFRP were crushed using a rotary mill (New Power Mill PM-2005, Osaka Chemical Co., Ltd., Osaka, Japan) and then sifted using a $0.5 \mathrm{~mm}$ or $\sim 0.5-1.0 \mathrm{~mm}$ mesh screen.

2. Crushed GFRP ( $\sim 0-60 \%$ of its total mass) was mixed with the clay.

3. The mixtures were solidified by pressing into a mold at $10 \mathrm{MPa}$.

4. The molded samples were heated in an oxidizing atmosphere at $100 \mathrm{~K} / \mathrm{h}$ to the firing temperature (1273 or $1373 \mathrm{~K}$ ) using an electric furnace (KY-4N, Kyoei 

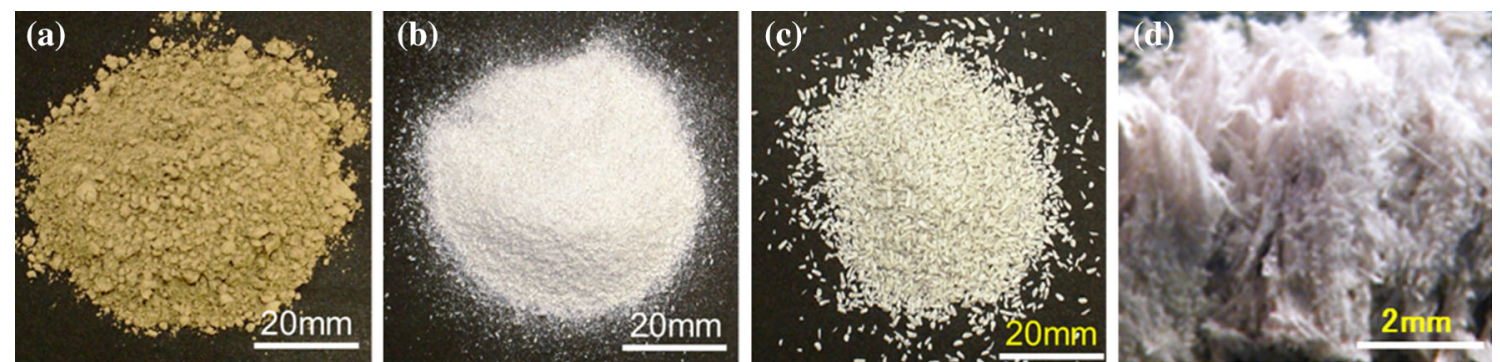

Fig. 1 a Clay, b polyamide plastic powder that contains $40 \%$ glass fiber (particle size: $\sim 0.5 \mathrm{~mm}$ ), c polyamide plastic powder (particle size: $\sim 0.5-1.0 \mathrm{~mm})$, d glass fiber in the GFRP

Table 1 Chemical compositions of inorganic substances contained in clay and GFRP

\begin{tabular}{lcc}
\hline Component & Clay (mass \%) & $\begin{array}{l}\text { Inorganic matter in } \\
\text { GFRP (mass \%) }\end{array}$ \\
\hline $\mathrm{SiO}_{2}$ & 65.8 & 45.5 \\
$\mathrm{Al}_{2} \mathrm{O}_{3}$ & 21.9 & 11.9 \\
$\mathrm{Fe}_{2} \mathrm{O}_{3}$ & 4.79 & 2.38 \\
$\mathrm{~K}_{2} \mathrm{O}$ & 3.37 & 0.19 \\
$\mathrm{MgO}$ & 1.67 & 0.83 \\
$\mathrm{CaO}$ & 1.31 & 37.1 \\
$\mathrm{Bal}$. & 0.87 & 1.00 \\
\hline
\end{tabular}

Table 2 Specimen types and specimen manufacturing conditions

\begin{tabular}{llll}
\hline & $\begin{array}{l}\text { Mixing rate } \\
\text { of GFRP } \\
(\text { mass } \%)\end{array}$ & $\begin{array}{l}\text { Particle size of } \\
\text { crushed GFRP } \\
(\mathrm{mm})\end{array}$ & $\begin{array}{l}\text { Firing } \\
\text { temperature } \\
(\mathrm{K})\end{array}$ \\
\hline T0 & 0 & - & 1273 \\
$\mathrm{~T} 1$ & 40 & $\sim 0.5$ & 1273 \\
$\mathrm{~T} 2$ & 60 & $\sim 0.5$ & 1273 \\
$\mathrm{~T} 3$ & 40 & $\sim 0.5-1.0$ & 1273 \\
$\mathrm{~T} 4$ & 60 & $\sim 0.5-1.0$ & 1273 \\
$\mathrm{~T} 5$ & 40 & $\sim 0.5$ & 1373 \\
$\mathrm{~T} 6$ & 40 & $\sim 0.5-1.0$ & 1373 \\
$\mathrm{~T} 7$ & 60 & $\sim 0.5-1.0$ & 1373 \\
\hline
\end{tabular}
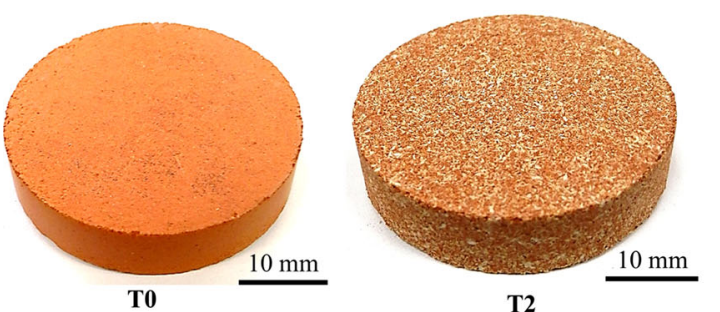

T2

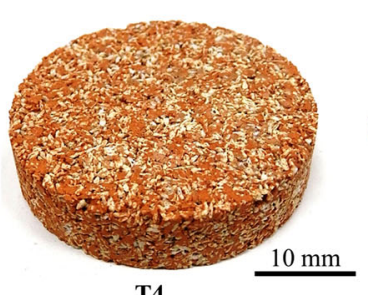

T4

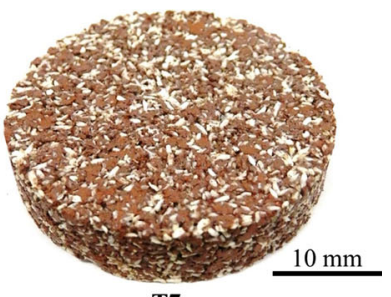

T7

Fig. 2 Various specimens (T0, T2, T4, and T7) made by changing the mixing ratio of GFRP and clay, the particle size of crushed GFRP, and the firing temperature 
Table 3 Chemical compositions of specimens made from clay and GFRP

\begin{tabular}{lccc}
\hline Component & \multicolumn{2}{c}{ Mixing rate of GFRP with $40 \%$ glass fiber (mass \%) } \\
\cline { 2 - 4 } & $20 \%$ & $40 \%$ & $60 \%$ \\
\hline $\mathrm{SiO}_{2}$ & 64.6 & 62.8 & 60.7 \\
$\mathrm{Al}_{2} \mathrm{O}_{3}$ & 21.2 & 20.5 & 19.7 \\
$\mathrm{Fe}_{2} \mathrm{O}_{3}$ & 4.53 & 4.26 & 3.73 \\
$\mathrm{~K}_{2} \mathrm{O}$ & 2.98 & 2.63 & 2.11 \\
$\mathrm{MgO}$ & 1.46 & 1.33 & 1.31 \\
$\mathrm{CaO}$ & 4.07 & 7.33 & 11.3 \\
$\mathrm{TiO}_{2}$ & 0.87 & 0.83 & 0.80 \\
\hline
\end{tabular}

on Japanese Industrial Standard JIS R2205 (Japanese Industrial Standards Committee 1992) and using a mercury porosimeter (Auto Pore IV 9500, Micromeritics Instrument Corporation, USA), respectively.

\section{pH measurement of solution after ceramic immersion}

To confirm that the liquid remaining after the turbid water had been filtered through the ceramic made from clay and waste GFRP would not affect the water quality adversely, we measured the solution $\mathrm{pH}$ after ceramic immersion based on the "Test Method for $\mathrm{pH}$ of Suspended Soils of the Japanese Geotechnical Society (JGS0211)" (Standards of the Japanese Geotechnical Society 2009). Specimens were dried in a furnace and were crushed to $\sim 1 \mathrm{~mm}$ or less. Powder specimens were immersed in distilled water with a mass of five times that of the powder for more than 30 min before the solution $\mathrm{pH}$ was measured.

\section{Strength test}

A high porosity is necessary so that the ceramic has a good permeability. The ceramic should also withstand some water pressure when it is used as a filtration material in turbid water. In general, it is difficult to make clay-based ceramics of high porosity because they may possess a good permeability but their strength decreases significantly with increase in porosity. Porous ceramics produced by mixing clay and GFRP may yield an extremely high porosity because the clay structure of the ceramic is reinforced by glass fiber. To prove this, we examined the strength of specimens T0-T7 (see Table 2), and that of some porous ceramics without glass fiber made by mixing polyamide (PA) resin powder with clay before firing. The specimen types and manufacturing conditions of the porous ceramics without glass fiber are described in Sect. 3.3.

We carried out four-point bending tests on each specimen. Specimens were $70 \mathrm{~mm}$ long, $20 \mathrm{~mm}$ wide, and

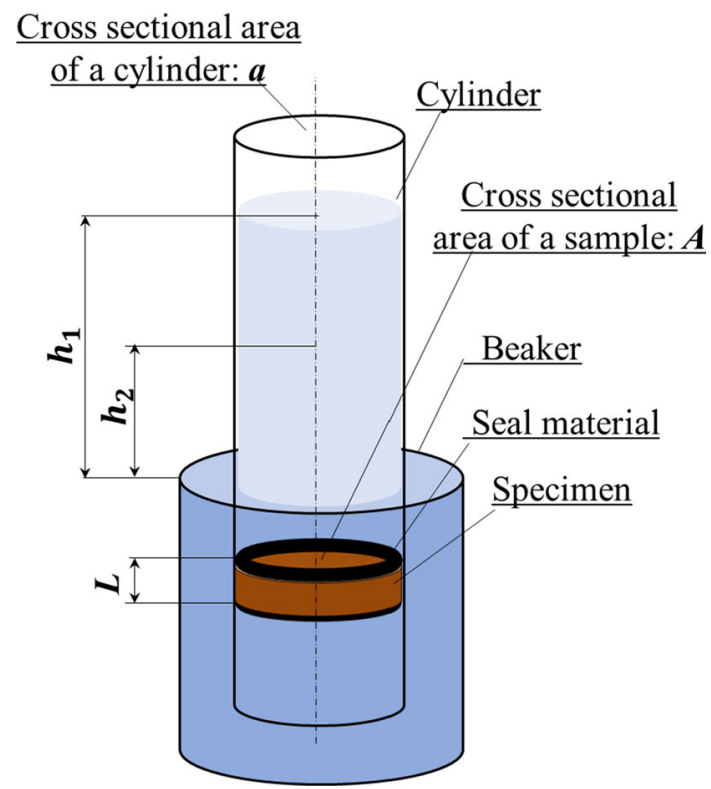

Fig. 3 Schematic illustration of the permeability test

$\sim 12 \mathrm{~mm}$ thick. Tests were performed using a universal testing machine (AG-X50kN, Shimadzu Corp., Japan) at a crosshead speed of $0.5 \mathrm{~mm} / \mathrm{min}$. The maximum bending stress was calculated using the following equation from the measured maximum load:

$\sigma_{f}=\frac{3 P(L-a)}{2 b h^{2}}$

where $P$ is the maximum load, $L$ is the $26 \mathrm{~mm}$ distance between the lower supporting points, $a$ is the $10 \mathrm{~mm}$ distance between the upper loading points, and $b$ and $h$ are the specimen rectangular cross-sectional width and depth, respectively.

\section{Permeability test method}

To examine the ceramic permeability, tests were carried out based on a falling head permeability test of soil in "Tests methods for permeability of saturated soils of the Japanese Industrial Standard (JIS A1218)" (Japanese Industrial Standards Committee 2009). Figure 3 shows a schematic illustration of the permeability test. The ceramic permeability was evaluated by calculating the coefficient of permeability:

$k_{T}=2.303 \frac{a L}{A\left(t_{2}-t_{1}\right)} \log _{10} \frac{h_{1}}{h_{2}}$

where $k_{T}$ is the coefficient of permeability $(\mathrm{cm} / \mathrm{s}), a$ is the cross-sectional cylinder area $\left(\mathrm{cm}^{2}\right), L$ is the specimen thickness $(\mathrm{cm}), A$ is the cross-sectional specimen area $\left(\mathrm{cm}^{2}\right)$, and $h_{1}$ and $h_{2}$ are the water level at times $t_{1}$ and $t_{2}$, respectively $(\mathrm{cm})$. 
In Fig. 3, the internal cylinder diameter was $4.6 \mathrm{~cm}$ and the cylinder cross-sectional area $a$ was $16.62 \mathrm{~cm}^{2}$. The specimen thickness $L$ was $1.0 \mathrm{~cm}$, and the net cross-sectional area $A$, excluding the area in which the specimen was covered with a seal material, was $8.41 \mathrm{~cm}^{2}$.

\section{Filtration test method using simulated turbid water}

The ceramic filtering ability is thought to depend on the size of the suspended matter and the size of the pores in the structure of the filtration material. Therefore, we used three kinds of simulated turbid water that contained different sizes of suspended matter in the filtration tests. Simulated turbid water that contains kaolin powder with an average particle size of $8 \mu \mathrm{m}$ and with a turbidity of $100^{\circ}$ was created based on the Testing Methods for Industrial Water of Japanese Industrial Standard (K0101) (Japanese Industrial Standards Committee 1998). The other samples were simulated turbid water that contains silica powder with an average particle size of $33 \mu \mathrm{m}$ and a particle size range of $\sim 100-300 \mu \mathrm{m}$. Figure 4 shows the particle size distributions of kaolin and silica powders with an average particle size of $33 \mu \mathrm{m}$. These were measured using a laser diffraction type of particle size distribution measuring apparatus (SALD-2100, Shimadzu Corp., Japan). The silica powder distribution with a particle size of $\sim 100-300 \mu \mathrm{m}$ was not measured. The kaolin powder particle size ranged from 0.5 to $30 \mu \mathrm{m}$, and that of the silica powder with a particle size of $33 \mu \mathrm{m}$ ranged from 5 to $100 \mu \mathrm{m}$.

Filtration tests were carried out using a permeability test cylinder. The specimen dimensions and shapes used in the filtration tests were the same as those used in the permeability tests (specimens were approximately $44 \mathrm{~mm}$ in diameter and $10 \mathrm{~mm}$ thick). Filtration tests were carried out by passing $100 \mathrm{~mL}$ of turbid water through a specimen with a net cross-sectional area of $8.41 \mathrm{~cm}^{2}$. The specimen was located in a cylinder.

In filtration tests using turbid water that contains kaolin powder, the turbidity of the used turbid water before and after filtering was measured, and the extent of reduction was calculated from the difference in turbidity. The turbidity of the simulated turbid water was measured using a Drainage Analyzer (NDR-2000, Nippon Denshoku Co., Ltd, Japan). In filtration tests using turbid water that contained silica powder, the filtering ability was evaluated from the difference in mass of suspended matter contained in the turbid water before and after filtering, because it was difficult to measure the water sample turbidity accurately.

\section{Results and discussions}

\section{Apparent porosity and pore size distributions}

Figure 5 shows the apparent porosities of the ceramics. We could produce various ceramics with porosities as high as $\sim 40 \%$ or more by mixing GFRP that contains $40 \%$ glass fiber with 40-60\% clay. The porosities of ceramics fired at $1273 \mathrm{~K}$ increased with increase in GFRP mixing ratio. This occurred because a larger amount of resin component was decomposed during firing with increasing mixing ratios of GFRP. Porosities of ceramics fired at $1373 \mathrm{~K}$ (specimen T7) and made by mixing $60 \%$ GFRP with particle sizes of $\sim 0.5-1.0 \mathrm{~mm}$ with clay had a slightly smaller porosity than specimens $\mathrm{T} 2$ and $\mathrm{T} 4$ made by firing a mixture of $60 \%$ GFRP with clay at $1273 \mathrm{~K}$.

Figure 6 shows the pore size distributions of the ceramics. Specimens made from clay alone had pores of several micrometers or less. In specimens (T1-T4), made by firing at $1273 \mathrm{~K}$, the pore sizes increase with increase in

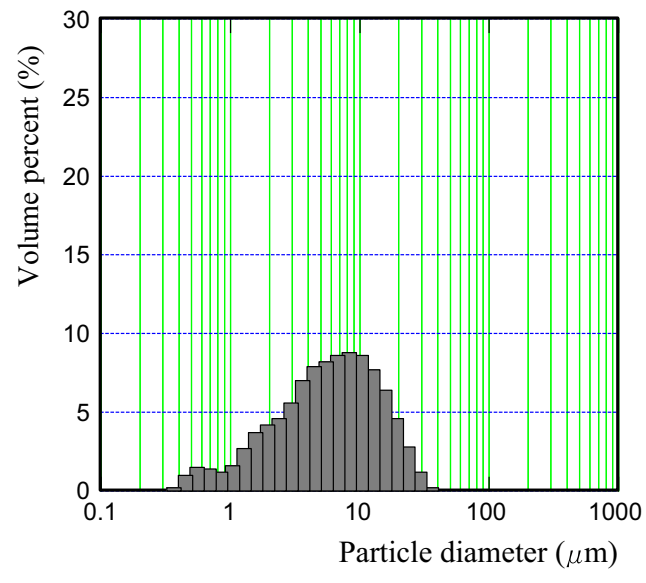

Kaolin powder

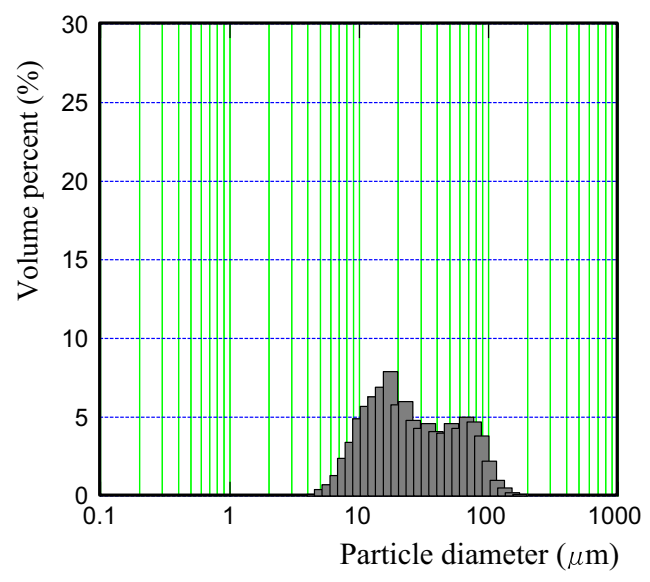

Silica powder

Fig. 4 Particle size distributions of kaolin and silica powders 
GFRP mixing ratio, and their pore sizes varied mainly from several micrometers to several hundreds of micrometers. To determine the influence of GFRP particle size on specimen pore size distribution, specimen T1 was compared with T3, and specimen T2 was compared with T4. Specimens made using $\sim 0.5-1.0 \mathrm{~mm}$ GFRP particles contained larger-sized pores than specimens made using GFRP of a particle size of $0.5 \mathrm{~mm}$ or less. Specimens (T5T7) made by firing at $1373 \mathrm{~K}$ contained many pores of a hundred micrometers or over.

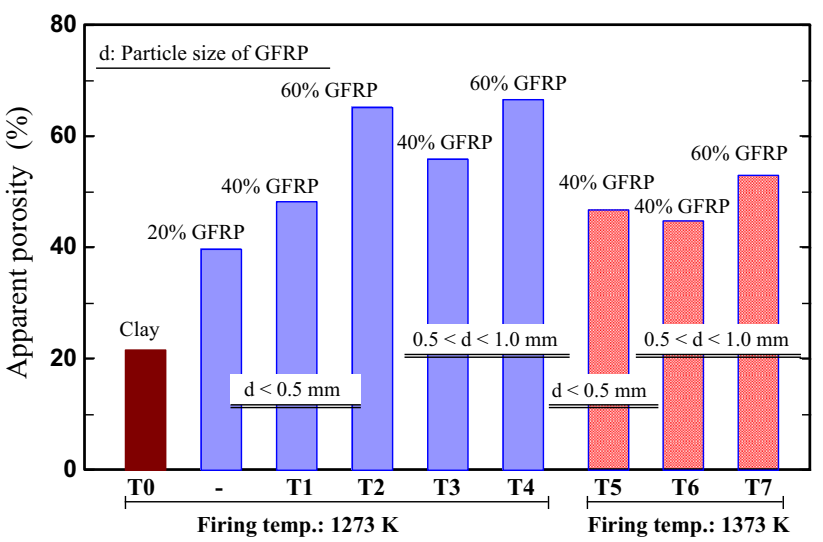

Fig. 5 Apparent specimen porosities
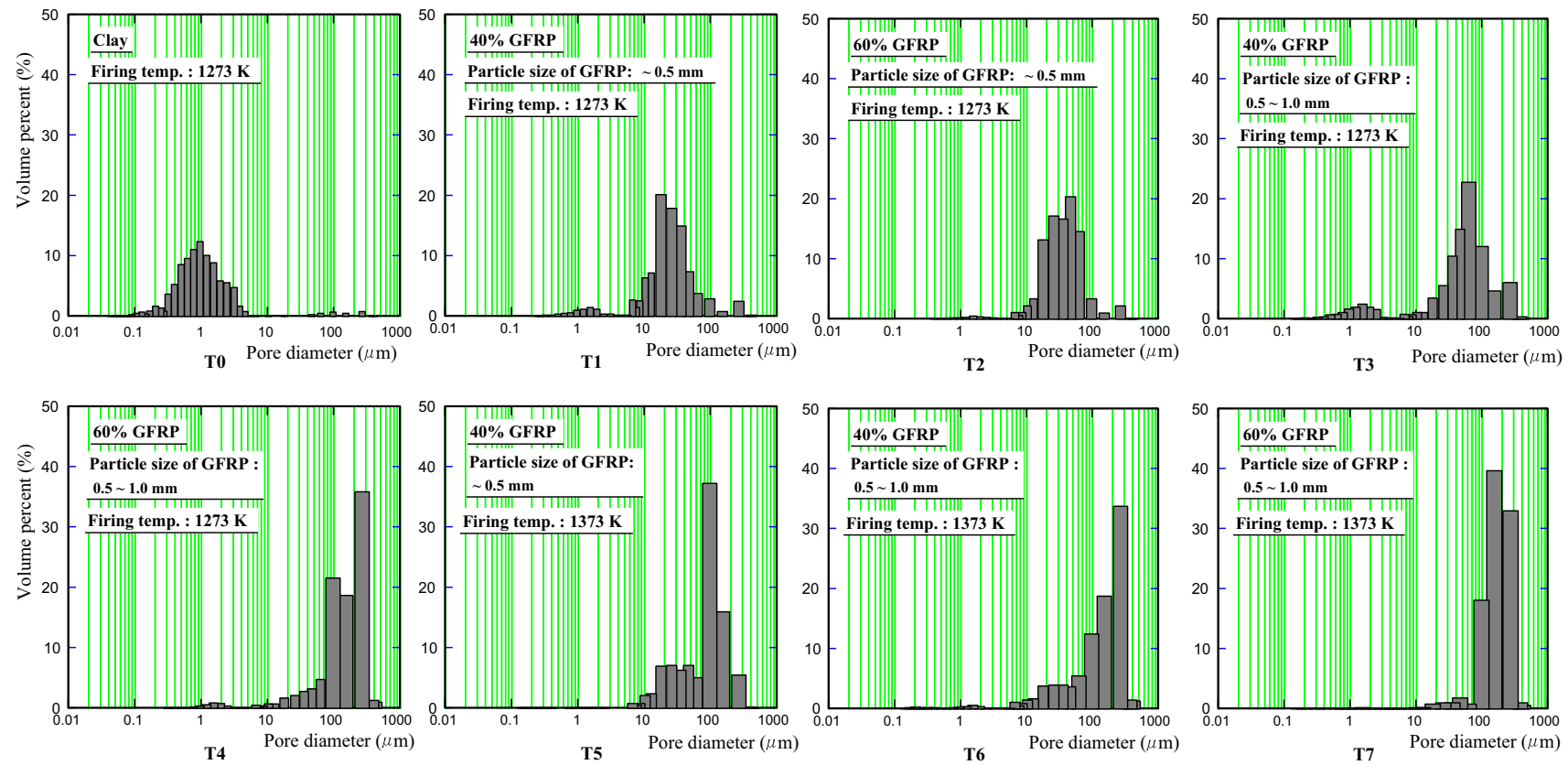

Fig. 6 Pore size distributions 
through the ceramic would not affect the water quality adversely.

\section{Ceramic bending strength}

Figure $8 \mathrm{a}, \mathrm{b}$ shows the bending strength of specimens made by mixing GFRP with clay. The heights of the bar graphs express the average values of the bending strength and the error bars show the standard deviation. Figure $8 \mathrm{c}, \mathrm{d}$ shows Weibull plots of the bending strength. For the diagram of Weibull plots, the $x$ - and $y$-axes express logarithms of bending strength and specimen cumulative failure probability $P$, respectively. The bending strength of specimens made by firing at $1273 \mathrm{~K}$ and that of specimens made by firing at $1373 \mathrm{~K}$ are shown separately. The bending strength of porous specimens without glass fiber made by mixing PA resin powder with clay is also shown with that of the clay/GFRP specimens. Porous specimens without glass fiber are shown as graphs $T_{A}, T_{B}$, and $T_{C}$. Specimen $T_{A}$ represents porous ceramics in which PA resin powder with a particle size of $0.5 \mathrm{~mm}$ or less was mixed with clay in a ratio of $24 \%$ before the mixture was fired at $1273 \mathrm{~K}$. Specimens $T_{B}$ and $T_{C}$ are porous ceramics in
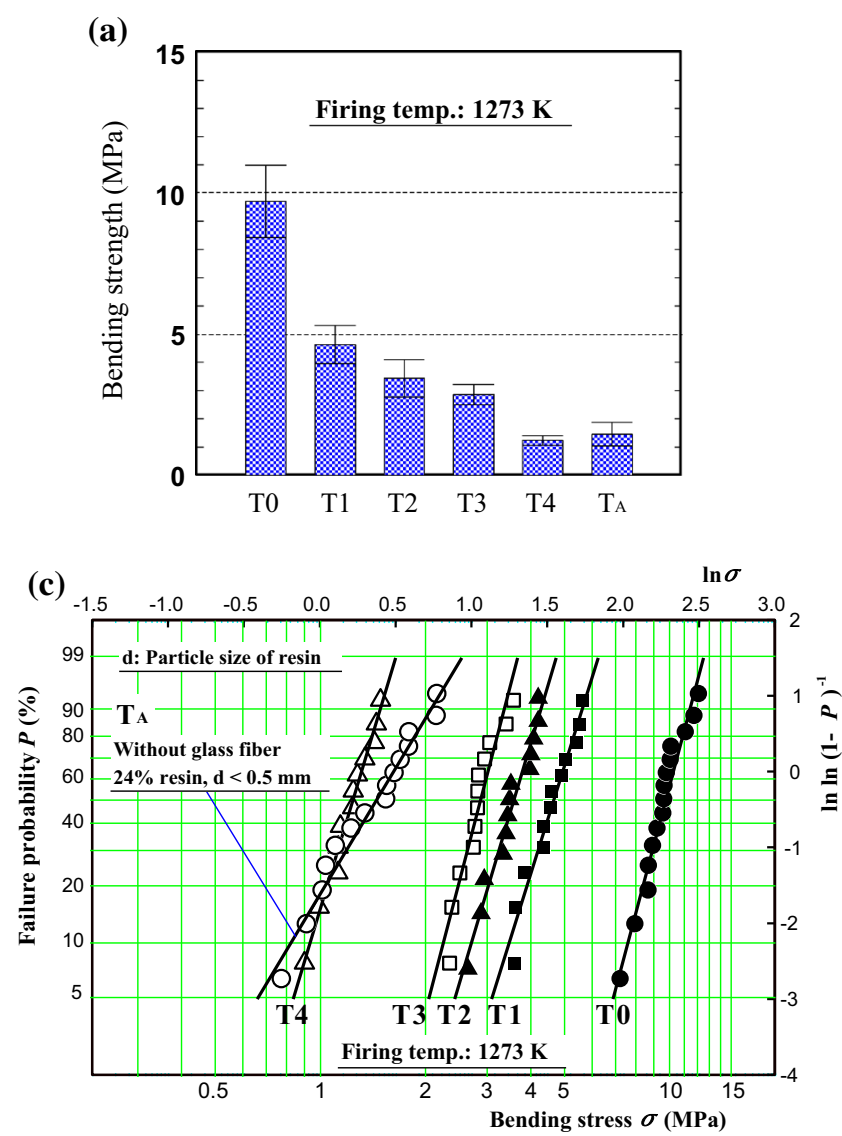

Fig. 8 Ceramic bending strength which PA resin powders with particle sizes of $\sim 0.5$ and $\sim 0.5-1 \mathrm{~mm}$, respectively, were mixed with clay in a ratio of $24 \%$ before the mixtures were fired at $1373 \mathrm{~K}$. For specimens containing glass fiber, the mixing ratio of the resin was $6 \%$ for mixtures of $10 \%$ GFRP with clay because the content of resin in the GFRP was $60 \%$. For example, the resin mixing ratio of the specimen made by mixing $40 \%$ GFRP with clay corresponds to $24 \%$.

The bending strength of specimens made by mixing GFRP with clay decreased as the mixing ratio of GFRP increased. This is because the amount of resin to total mass also increased as the mixing ratio of GFRP increased. This occurs because the void space in the specimen structure increased because a larger amount of resin decomposed during firing, so that the bending strength decreased. The specimen bending strength also decreased with increase in resin particle size.

A comparison of the bending strength of specimen $\mathrm{T} 1$ with that of specimen $T_{A}$ shows that the bending strength of specimen $\mathrm{T} 1$ that contains glass fiber was considerably higher than that of specimen $T_{A}$ without glass fiber. Similarly, a comparison of the bending strength of specimen T5 that contains glass fiber with that of specimen $T_{B}$ without
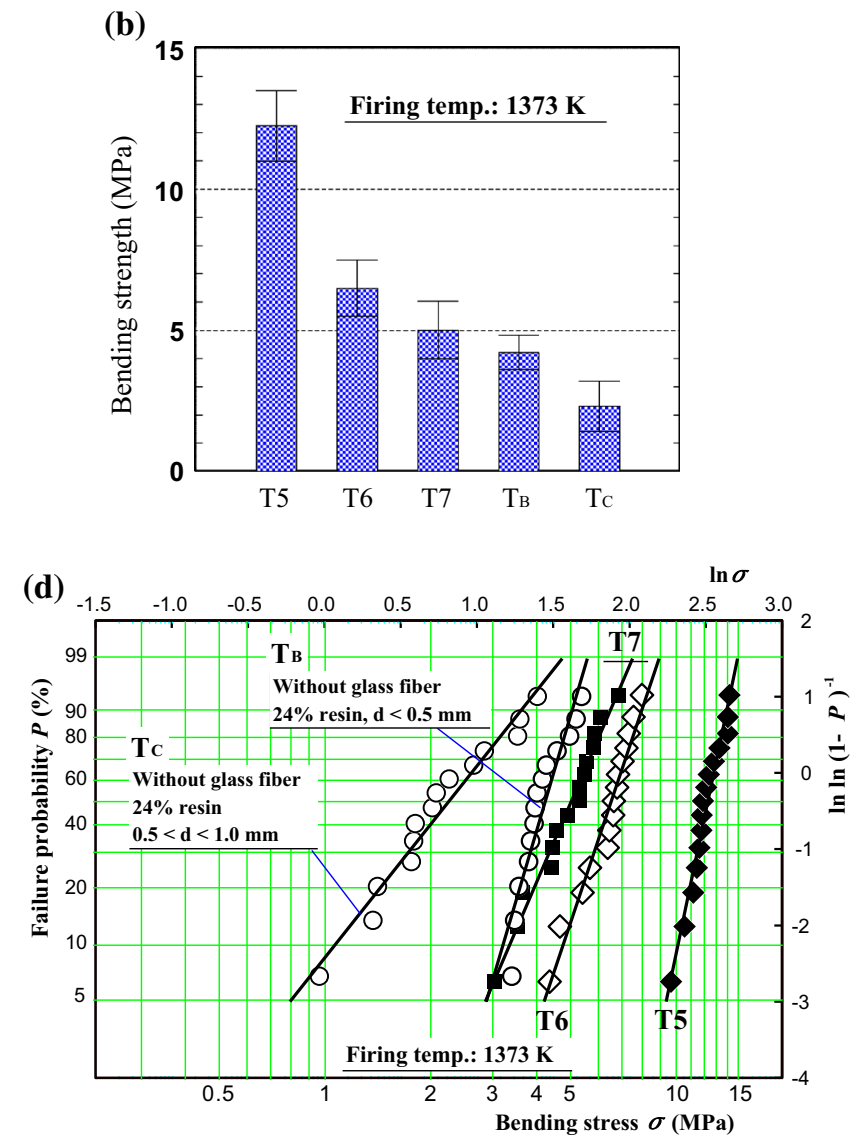
glass fiber, and the bending strength of specimen T6 with that of specimen $T_{C}$, shows that the structures of specimens made by mixing GFRP with clay were reinforced significantly by the glass fiber.

We could not produce ceramics by mixing PA resin powder with a particle size of $\sim 0.5-1.0 \mathrm{~mm}$ with clay in a ratio of $24 \%$ before the mixture was fired at $1273 \mathrm{~K}$. It was difficult to produce porous ceramics at the resin mixing ratio larger than $24 \%$ because of the poor strength of the material that contains resin without glass fiber mixed with clay. Where GFRP powder was mixed with clay, we could produce adequate ceramics, as shown by specimens $\mathrm{T} 2$, T4, and T7, because the ceramic structure was reinforced by glass fiber. Mixing GFRP powder with clay enables us to produce ceramics that possess extremely high porosities and a larger pore size in the structure. As described in Sect. 3.4, ceramics that possess high porosities or large-sized pores also allow for water passage. This is a great advantage of using waste GFRP as a raw material to produce filtration materials.

\section{Ceramic permeability}

Figure 9 shows the specimen coefficients of permeability. As reference, a water-permeable paving block has a coefficient of permeability of $0.01 \mathrm{~cm} / \mathrm{s}$ and higher (Architectural Institute of Japan 2009). The result shown in Fig. 9 indicates that water can pass through the specimens made from clay and GFRP although it can barely pass through specimens made from clay alone. For ceramic specimens made from GFRP and clay, it is believed that combustion gas formed many interconnected pores in the ceramic structure when the plastic component was decomposed during firing.

For specimens (T1-T4) made by firing at $1273 \mathrm{~K}$, specimen T4 had the largest coefficient of permeability and specimen T2 had the second largest. This is thought to occur because specimens T2 and T4 had higher porosities

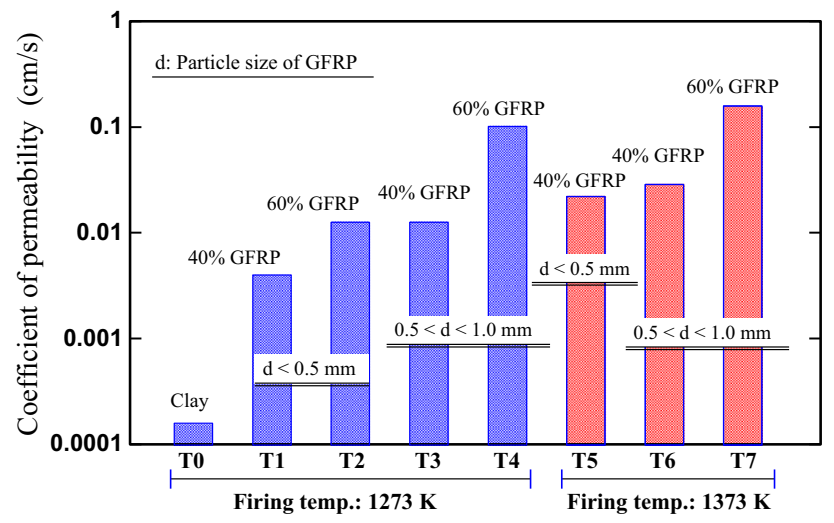

Fig. 9 Comparison of permeability for various specimens compared with those of other specimens, as shown in Fig. 5, and specimen T4 had relatively larger-sized pores in its structure than specimen $\mathrm{T} 2$. These results indicate that the specimen permeability depends on its porosity and pore size. It is likely that specimens (T5-T7) made by firing at $1373 \mathrm{~K}$ also had relatively high permeabilities because of their relatively large pore sizes. Therefore, specimens T2T7 exhibit good permeabilities. It was verified that several types of ceramics with good permeabilities but different pore size distributions could be made from GFRP and clay.

\section{Ceramic filtering ability}

\section{Ceramic filtering ability for simulated turbid water}

Figure 10a shows the reduction in turbidity when $100 \mathrm{~mL}$ of $100^{\circ}$ simulated turbid water that contains $\sim 0.5-30 \mu \mathrm{m}$ kaolin powder was filtered through each ceramic specimen. Figure 10b, c shows the filtration rate when $100 \mathrm{~mL}$ of simulated turbid water that contains $0.1 \mathrm{~g}$ silica powder of $\sim 5-100$ or $\sim 100-300 \mu \mathrm{m}$ was filtered through each ceramic specimen. Figure 10d shows the specimens after filtering. The appearance of specimen T2 in Fig. 10d shows that when $1 \mathrm{~L}$ of simulated turbid water was filtered, silica powder accumulated more easily on the specimen surface by filtration, because $\sim 0.1 \mathrm{~g}$ silica powder was contained in $100 \mathrm{~mL}$ of simulated turbid water.

In the filtration tests for the turbid water that contained $\sim 0.5-30 \mu \mathrm{m}$ kaolin powder (Fig. 10a), specimens T1 and T2 exhibited high turbidity reduction rates. In contrast, those of specimens T4, T6, and T7 were very low. In the filtration tests for turbid water that contains $\sim 5-100 \mu \mathrm{m}$ silica powder (Fig. 10b), the filtration rates of specimens T3-T7 increased to $\sim 50-80 \%$. In the filtration tests for turbid water that contains $\sim 100-300 \mu \mathrm{m}$ silica powder (Fig. 10c), all specimens exhibited high filtration rates of $\sim 80-90 \%$. Most suspended matter that could not pass through the specimen accumulated on the specimen surface, as shown in Fig. 10d.

The filtration test results are explained as follows. From the specimen pore size distributions shown in Fig. 6, it is believed that the turbidity reduction rates of specimens $\mathrm{T} 4$, T6, and T7 for turbid water that contains kaolin powder were low because they contained many larger pores than the kaolin particle size. For turbid water that contains $\sim 100-300 \mu \mathrm{m}$ silica powder, it is believed that all specimens had very high filtration rates because they had smaller pores than those of the silica powder. It is thought that suspended matter that is larger than the ceramic structure pore size was filtered.

A smaller ceramic structure pore size results in a higher filtration rate because suspended matter passes through the ceramic structure less easily. However, the ceramic 
(a)

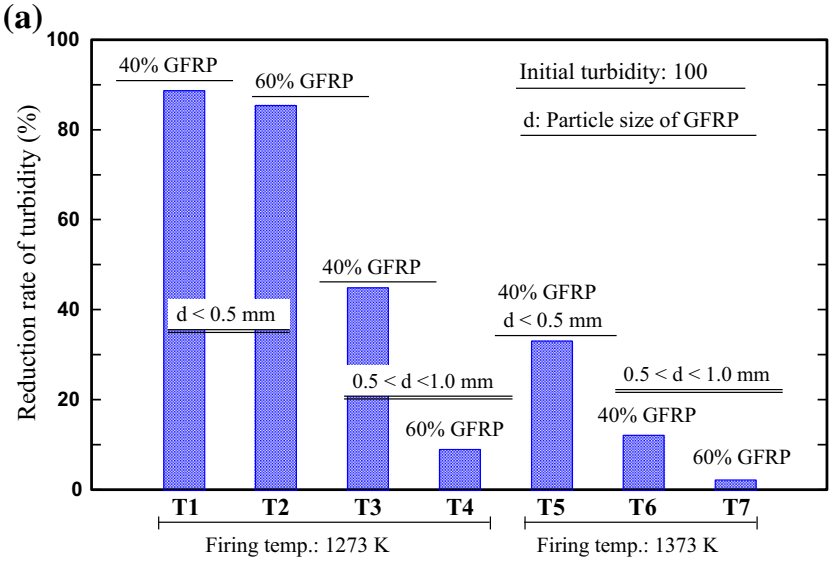

(c)

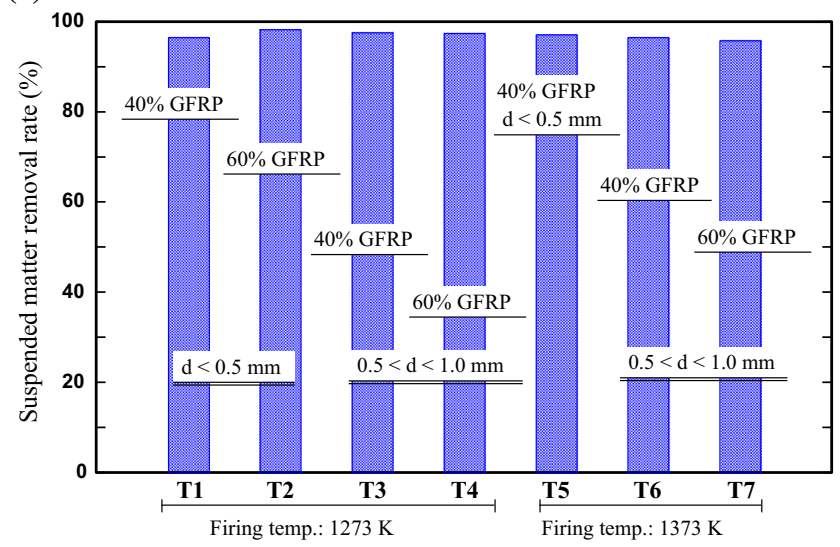

Fig. 10 Results of filtration tests using two kinds of simulated turbid water. a Filtration of turbid water containing $\sim 0.5-30 \mu \mathrm{m}$ kaolin powder, b filtration of turbid water containing $\sim 5-100 \mu \mathrm{m}$ silica

permeability deteriorates. In terms of filtering material performance, it is desirable to have a high permeability and a high filtering ability for suspended matter. Some ceramics made from GFRP and clay meet both requirements.

We carried out circulating filtration tests on simulated turbid water that contains kaolin powder on specimen T4, which exhibited a low turbidity reduction rate when turbid water was filtered in a single pass through the specimen, as shown in Fig. 10a. Turbid water $(10 \mathrm{~L})$ with an initial turbidity of approximately $100^{\circ}$ was circulated through specimen $\mathrm{T} 4$ at $\sim 0.72 \mathrm{~L} / \mathrm{min}$. Figure 11 shows the turbidity change. Specimen T4 can decrease the turbidity of water that contains kaolin powder by recirculating filtration, although the turbidity reduction rate is low when the turbid water is filtered in a single pass. In this case, it is thought that the suspended matter was caught mechanically in the specimen structure.

Material accumulated on the filter and that held in the structure after filtering may cause clogging. Clogging

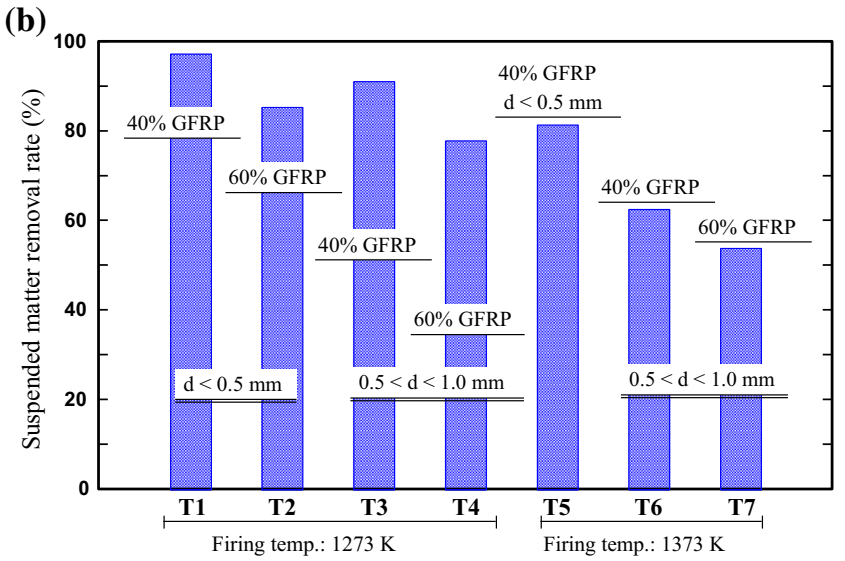

(d)

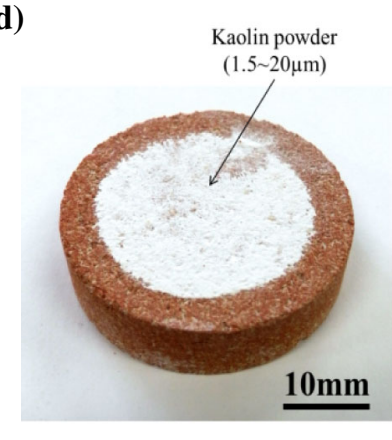

T2

After filtration test using turbid water containing kaolin powder

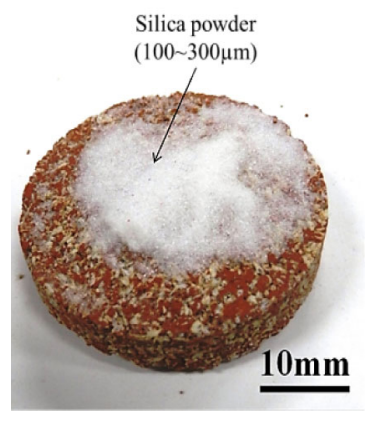

T4

After filtration test using turbid water containing silica powder powder, c filtration of turbid water containing $\sim 100-300 \mu \mathrm{m}$ silica powder, $\mathbf{d}$ specimen appearance after filtration tests

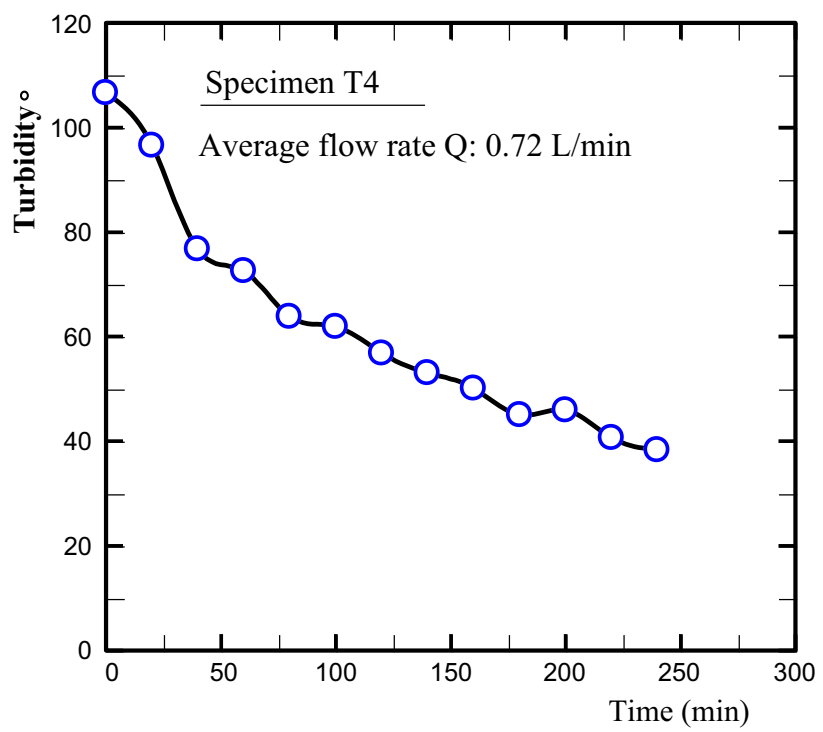

Fig. 11 Turbidity change by repetitive filtration 
caused by the accumulated material on the filter after filtering can be prevented to some degree by removing it from the filter. However, clogging caused by the material held in the filter structure cannot be prevented easily. Such a filtering mechanism is unsuitable because the suspended matter is caught mechanically in the filtration material structure. It is thought that the filters that we have produced can be used to filter turbid water without clogging over a short time by using selective ceramics with various pore size distributions in response to the sizes of suspended matter in turbid water. Ceramic properties could be adjusted by changing the mixing ratio of GFRP and clay, the particle size of crushed GFRP, and the firing temperature of ceramics.

\section{Filtering ability of ceramics for river water}

Results from filtration tests using simulated turbid water indicate that some ceramics made from waste GFRP and clay exhibited high filtering abilities for turbid water. To verify their practical suitability as filtration materials, we carried out filtration tests using Yae River water, which flows in Miyazaki, Japan.

Figure 12a shows that suspended matter of $\sim 10-600 \mu \mathrm{m}$ particle size (average particle size of $97 \mu \mathrm{m}$ ) is contained in the river water. The river water turbidity was $34^{\circ}$ and its $\mathrm{pH}$ was 7.6. Specimens $\mathrm{T} 2, \mathrm{~T} 3$, and $\mathrm{T} 4$ were used in the filtration tests, which were conducted by passing $1.7 \mathrm{~L}$ of river water through each specimen. Figure $12 \mathrm{~b}$ shows reduction rates in turbidity and the river water $\mathrm{pH}$ after filtering. The river water turbidity reduction rates yielded similar results to those from filtration tests on simulated turbid water that contains $\sim 5-100 \mu \mathrm{m}$ silica powder (see Fig. 10b). It is believed that the ceramics exhibit comparatively high turbidity reduction rates because the river water contained suspended matter that was larger than the pores in the ceramic structure. The river water $\mathrm{pH}$ after filtering confirms that the filtered river water quality changed only slightly. Therefore, their practical applicability as ceramic filtration materials has been verified.

\section{Conclusions}

To examine the suitability of porous ceramics made using waste GFRP and clay as filtering materials for turbid water, specimens with various porosities and pore sizes were created by changing the mixing ratio of clay and crushed GFRP, the GFRP particle size, and the mixture firing temperature. Permeability and filtration tests on turbid water were carried out using the samples. The results indicated the following:

1. The permeability tests showed that ceramics with permeabilities of $0.01 \mathrm{~cm} / \mathrm{s}$ and higher could be made from crushed GFRP and clay.

2. Ceramic filtration tests conducted using simulated turbid water confirmed that ceramics could filter suspended matter larger than the pore size in their structures. Turbid water that contains various sizes of suspended matter could be filtered by changing the mixing ratio of crushed GFRP with clay, the particle size of crushed GFRP, and the ceramic firing temperature.

3. It is expected that some ceramics made from GFRP and clay could be used as filtering materials for turbid (a)

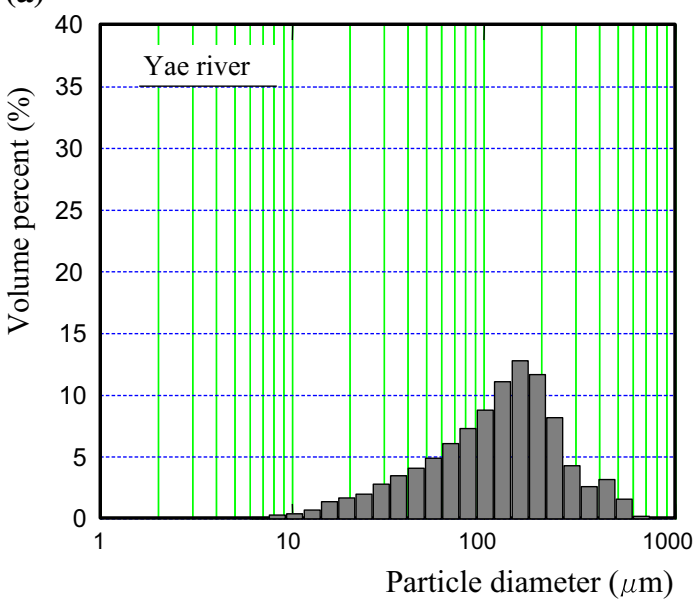

(b)

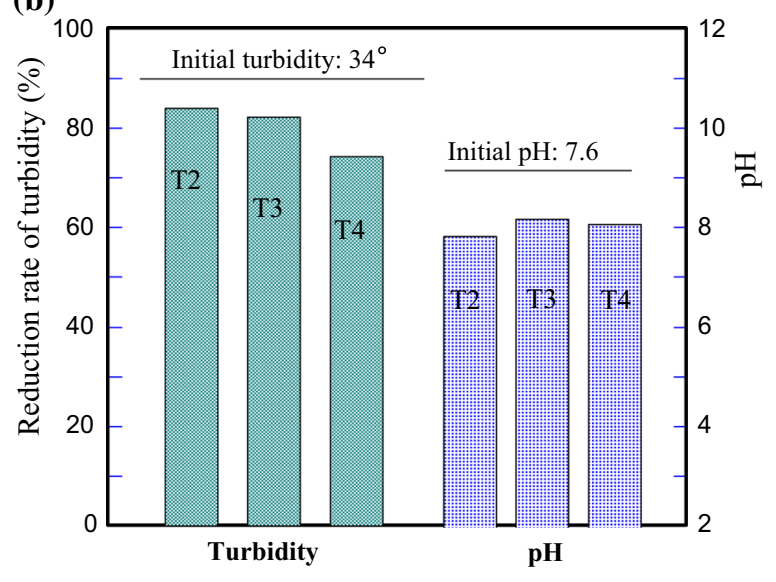

Fig. 12 Results from filtration tests on river water 
water because they exhibit a high permeability and filtering ability.

Acknowledgments The support provided by JKA Ring-Ring-Project (JKA26-130) is gratefully appreciated. This work was also supported by JSPS KAKENHI Grant Number 16K00614. We would like to thank Ikeda Engineering Co. Ltd. for providing the plastics.

Open Access This article is distributed under the terms of the Creative Commons Attribution 4.0 International License (http://crea tivecommons.org/licenses/by/4.0/), which permits unrestricted use, distribution, and reproduction in any medium, provided you give appropriate credit to the original author(s) and the source, provide a link to the Creative Commons license, and indicate if changes were made.

\section{References}

Architectural Institute of Japan (2009) Japanese Architectural Standard Specification JASS 7 Masonry Work. Maruzen-Yushodo Co., Ltd., Tokyo, pp 335-337

Japanese Industrial Standards Committee (1992) Testing method for apparent porosity, water absorption, specific gravity of refractory bricks. Jpn Ind Stand: JIS R2205:1-4

Japanese Industrial Standards Committee (1998) Testing methods for industrial water. Jpn Ind Stand K0101:1-314

Japanese Industrial Standards Committee (2009) Tests methods for permeability of saturated soils. Jpn Ind Stand: JIS A1218:1-8

Kinoshita H, Kaizu K, Takeda T, Miyagi H, Kawamura R, Ikeda K (2010) Development of high-strength porous tile by recycling of waste glass fiber-reinforced plastics. Trans Jpn Soc Mech Eng Ser A 76(771):1507-1513 (in Japanese)

Kinoshita H et al (2011) Development of high-strength porous tiles produced by recycling glass fibers in waste GFRP - influence of particle size of GFRP on tile properties. J JSEM 11(3):241-248 (in Japanese)

Kinoshita $\mathrm{H}$ et al (2013) Production and material properties of ceramic from waste glass fiber-reinforced plastic. J Environ Eng 8(1):27-40. doi:10.1299/jee.8.27

Materials science society of Japan (1999) Global environment and materials. Shokabo Co., Ltd., Tokyo, pp 61-74

Nagaoka T (2008) Value-added recycling of disposal plastics. J JSTP 49(566):175-179 (in Japanese)

Plastic Waste Management Institute of Japan (2013) An introduction to plastic recycling, pp 1-33. Web. https://www.pwmi.or.jp/ei/ plastic_recycling_2013.pdf. Accessed 04 Mar 2016

Plastic Waste Management Institute of Japan (2015) Plastic products, plastic waste and resource recovery. PWMI Newsl 44:1-10. Web. https://www.pwmi.or.jp/ei/siryo/ei/ei_pdf/ei44.pdf. Accessed 04 Mar 2016

Standards of the Japanese Geotechnical Society (2009) Test method for $\mathrm{pH}$ of suspended soils. JGS0211-2000, pp 1-3

The Ministry of the Environment Government of Japan (2013) The present conditions of the environmental pollution in China. Web. https://www.env.go.jp/air/tech/ine/asia/china/OsenCH.html

The Ministry of the Environment Government of Japan (2015) On the environment, the sound material-cycle society, and biodiversity in Japan 2015, pp 1-40

Yang Y, Boom R, Irion B, Heerden D, Kuiper P, Wit H (2012) Recycling of composite materials. Chem Eng Process 51:53-68 